\title{
LETTERS
}

doi:10.1017/S1041610210001171

\section{Could reverse causality or selective mortality explain associations between leg length, skull circumference and dementia? A South Indian cohort study}

In cross-sectional studies, skull circumference and leg length are often inversely associated with dementia prevalence (Prince et al., in press). Skull circumference and leg length are thought to remain stable across the adult life course, but the associations might yet be explained by reverse causality. Weight loss in dementia could lead to loss of subcutaneous scalp fat. Osteoporosis mainly affects trunk proportions (loss of disc space, vertebral fractures and kyphosis), but limited knee extension could also lead to apparent reductions in leg length. No previous studies have assessed changes in these measurements over time in older people with and without dementia. Only two cohort studies have examined the effect of skull circumference (Borenstein et al., 2001) and knee height (Huang et al., 2008) on incident dementia. Even in cohort studies differential mortality can lead to bias.

Accordingly, in a population-based cohort study of older people in Chennai, India we aimed to answer five questions

For reverse causality:

1. Do leg lengths and skull circumferences shrink with age?

2. Are these process more marked in those with dementia?

3. Is change in leg length and skull circumference correlated with cognitive decline?

For mortality bias

1. Are leg length and skull circumference associated with mortality?

2. Are these associations modified by dementia status?

The 10/66 Dementia Research Group baseline survey in Chennai, carried out between 2004 and 2006, included 1005 people aged 65 years and over, with a response rate of $72 \%$. Followup was conducted between December 2007 and July 2008, when we sought to re-interview all those with 10/66 dementia (Prince et al., 2003) or DSM-IV dementia at baseline $(\mathrm{n}=75)$, and those with cognitive impairment but no dementia $(n=193)$. Interviewers were masked to baseline status of follow-up participants. We also sought to trace all 1005 participants from the baseline survey to determine deaths and the date on which they occurred. Ethical approval was obtained in London and Chennai. At baseline and follow-up, skull circumference was measured using a cloth tape measure encircling the nuchal tuberosity and brow, and leg length was measured, standing, from the highest point of the iliac crest to the lateral malleolus. Cognitive function was assessed at baseline and follow-up using the Community Screening Assessment for Dementia (CSI'D') COGSCORE (Hall et al., 1993).

We re-examined 131 participants, 24/74 (32.4\%) of those with dementia, and 107/192 (55.7\%) with cognitive impairment. Fifty-five participants had died, 68 had moved away and 12 were traced but interviews could not be arranged. None refused reassessment. Baseline skull circumferences and leg lengths, age, gender and education were similar for those who were re-examined and those who were not (Table 1). Re-examinations took place a mean of 3.1 (range 2.4-4.7) years after baseline. The intraclass correlation coefficient for paired measurements of skull circumference was 0.74 (95\% CI 0.65 to 0.81 ) and for leg length was 0.85 (95\% CI 0.79 to 0.89 ). Paired t-tests indicated a decline over time in leg length (mean difference $-0.71 \mathrm{~cm}, 95 \% \mathrm{CI}-0.11$ to $-1.32 \mathrm{~cm}$ ), but not skull circumference (mean difference $-0.22 \mathrm{~cm}$, $95 \% \mathrm{CI}-0.51$ to $+0.07 \mathrm{~cm}$ ). Change in leg length was significantly associated with duration of followup, at a predicted rate of $-1.1 \mathrm{ccm}$ per year $(95 \%$ CI -1.8 to $0.0 \mathrm{~cm}$ ). Controlling for age, gender, education and duration of follow-up, there was no difference in mean change in skull circumference between those with dementia, and those with CIND (mean difference $+0.20 ; 95 \%$ CI -0.59 to +0.99 ) or the mean change in leg length (mean difference $+0.20 ; 95 \%$ confidence intervals -1.45 to +1.85 ). Neither change in skull circumference (Pearson's correlation coefficient $-0.07, \mathrm{p}=0.13$ ), nor change in leg length (Pearson's correlation coefficient $-0.06, \mathrm{p}=0.55)$, was correlated with change in cognitive function (CSI'D' COGSCORE).

We could not determine vital status for 257/1005 participants at baseline, of whom 229 had been displaced by a major infrastructural development. Of the remaining 748 participants, 154 had died. Adjusting for age, education and gender, neither leg length (hazard ratio (HR) per $\mathrm{cm} 1.01 ; 95 \%$ CI 0.98 to 1.04 ) nor skull circumference (HR, per $\mathrm{cm} 0.95 ; 95 \%$ CI 0.88 to 1.02 ) were associated 
Table 1. Baseline characteristics of participants interviewed and not interviewed in the follow-up phase

\begin{tabular}{|c|c|c|c|c|c|c|c|c|}
\hline \multirow[b]{4}{*}{ CHARACTERISTIC } & \multicolumn{4}{|c|}{ COGNITIVE IMPAIRMENT } & \multicolumn{4}{|c|}{ DEMENTIA } \\
\hline & & & & $\begin{array}{l}\text { STATISTICAL } \\
\text { TEST FOR }\end{array}$ & & & & $\begin{array}{l}\text { STATISTICAL } \\
\text { TEST FOR }\end{array}$ \\
\hline & & & NOT & RE-EXAMINED & & & NOT & RE-EXAMINED \\
\hline & $\begin{array}{l}\text { ALL } \\
(\mathrm{N}=193)\end{array}$ & $\begin{array}{l}\text { RE-EXAMINED } \\
(\mathrm{N}=107)\end{array}$ & $\begin{array}{l}\text { RE-EXAMINED } \\
(\mathrm{N}=86)\end{array}$ & $\begin{array}{l}\text { VS. NOT } \\
\text { RE-EXAMINED }\end{array}$ & $\begin{array}{l}\text { ALL } \\
(\mathrm{N}=75)\end{array}$ & $\begin{array}{l}\text { RE-EXAMINED } \\
(\mathrm{N}=24)\end{array}$ & $\begin{array}{l}\text { RE-EXAMINED } \\
(\mathrm{N}=51)\end{array}$ & $\begin{array}{l}\text { VS. NOT } \\
\text { RE-EXAMINED }\end{array}$ \\
\hline Age (mean) & $71.2(5.5)$ & $71.1(5.2)$ & $71.3(5.7)$ & $\begin{array}{l}\mathrm{T}=0.3,190 \mathrm{df} \\
\mathrm{p}=0.80\end{array}$ & $75.3(8.1)$ & $75.3(8.5)$ & $75.5(7.5)$ & $\begin{array}{l}\mathrm{T}=-0.1,73 \mathrm{df} \\
\mathrm{p}=0.93\end{array}$ \\
\hline Female gender & $103(54.2 \%)$ & $56(52.3)$ & $47(56.6 \%)$ & $\begin{array}{l}\chi^{2}=0.20,1 \mathrm{df} \\
\mathrm{p}=0.66\end{array}$ & $47(62.7 \%)$ & $18(75.0 \%)$ & $29(56.9 \%)$ & $\begin{array}{l}\chi^{2}=1.6,1 \mathrm{df} \\
\mathrm{p}=0.21\end{array}$ \\
\hline \multicolumn{9}{|l|}{ Education } \\
\hline None & $75(39.1 \%)$ & $41(38.3 \%)$ & $34(40.0 \%)$ & $\begin{array}{l}\chi^{2}=0.0,1 \mathrm{df} \\
\mathrm{p}=0.86\end{array}$ & $44(58.7 \%)$ & $15(62.5 \%)$ & $29(56.9 \%)$ & \multirow[t]{4}{*}{$\begin{array}{l}\chi^{2}=0.55,1 \mathrm{df} \\
\mathrm{p}=0.46\end{array}$} \\
\hline Some & $49(25.5 \%)$ & $28(26.2 \%)$ & $21(24.7 \%)$ & & $9(12.0 \%)$ & $3(12.5 \%)$ & $6(11.8 \%)$ & \\
\hline Primary & $33(17.2 \%)$ & $18(16.8 \%)$ & $15(17.6 \%)$ & & $19(25.3 \%)$ & $6(25.0 \%)$ & $13(25.5 \%)$ & \\
\hline Secondary/tertiary & $35(18.2 \%)$ & $20(18.7 \%)$ & $15(17.6 \%)$ & & $3(4.0 \%)$ & $0(0.0 \%)$ & $3(5.9 \%)$ & \\
\hline $\begin{array}{l}\text { Skull circumference } \\
\mathrm{cm} \text { (mean) }\end{array}$ & $53.1(2.4)$ & $52.9(2.6)$ & $53.3(2.1)$ & $\begin{array}{l}\mathrm{T}=1.0,189 \mathrm{df} \\
\mathrm{p}=0.32\end{array}$ & $52.9(2.2)$ & $53.1(2.2)$ & $52.8(2.2)$ & $\begin{array}{l}\mathrm{T}=-0.4,70 \mathrm{df} \\
\mathrm{p}=0.65\end{array}$ \\
\hline $\begin{array}{l}\text { Leg length } \mathrm{cm} \\
\text { (mean) }\end{array}$ & $91.1(6.5)$ & $90.6(6.7)$ & $91.7(6.3)$ & $\begin{array}{l}\mathrm{T}=1.1,179 \mathrm{df} \\
\mathrm{p}=0.29\end{array}$ & $90.6(6.1)$ & $91.5(3.9)$ & $90.1(6.9)$ & $\begin{array}{l}\mathrm{T}=-0.88,66.3 \mathrm{df}, \\
\mathrm{p}=0.30\end{array}$ \\
\hline
\end{tabular}


with mortality. The hazard ratios for the interaction terms between dementia status and leg length (0.93: $95 \%$ CI 0.86 to 1.01 ) and dementia status and skull circumference $(0.86 ; 95 \%$ CI 0.69 to 1.06$)$ were also not statistically significant.

In our sample, leg lengths shrank over time, but at a similar rate among people with dementia, and those with cognitive impairment but no dementia. Reductions in leg length may reflect decreasing ability to extend the lower limb rather than changes in skeletal dimensions. Skull circumferences do not seem to shrink over time, again not modified by dementia status. Cognitive decline is not associated with change in either leg length or skull circumference. While skull circumferences show no directional trend for change over time, repeated measures are less stable than repeated measures of leg length, probably because of greater measurement error. There is therefore no evidence that reverse causality - dementia causing skulls and legs to shrink - can account for inverse associations between skull circumference and leg length, and dementia. Loss to follow-up and small sample size both limit the inferences to be drawn from these negative findings. Lack of precision may have resulted in type 2 error or bias in differences in change in dimensions between those with and without dementia. Also, repeated measures of skulls and legs were not carried out in the baseline sample of people with normal cognitive function. Had leg lengths not shrunk in this group, then our findings could still be consistent with reverse causality. However, for the association with skull circumference to be accounted for by reverse causality, skull circumferences would have had to increase in those without cognitive impairment. Neither baseline skull circumference nor leg length was associated with mortality, with no effect modification by dementia status. The direction of the trend in the interaction terms suggests that mortality bias would, if anything, have led to an underestimation of any protective

doi:10.1017/S1041610210002036

\section{The needle has been blunt for $\mathbf{2 0}$ years}

The growing need for lumbar puncture in order to obtain cerebrospinal fluid (CSF) for the diagnosis Alzheimer's disease is becoming increasingly apparent (Herskovits and Growdon, 2010). The concept of a CSF sampling unit specializing in lumbar puncture would seem the most plausible solution. Physicians and interns are not necessarily skilled in the proced- effect of longer legs and larger skulls on dementia incidence.

\section{Acknowledgments}

This study was funded by the Wellcome Trust as a Health Consequences of Population Change Programme Master's level fellowship for A. T. Jotheeshwaran (GR081343). The baseline phase of the project was supported by the World Health Organization.

\section{References}

Borenstein, G. A. et al. (2001). Head circumference and incident Alzheimer's disease: modification by apolipoprotein E. Neurology, 57, 1453-1460.

Hall, K. S. et al. (1993). The development of a dementia screeing interview in two distinct languages. International Fournal of Methods in Psychiatric Research, 3, 1-28.

Huang, T. L., Carlson, M. C., Fitzpatrick, A. L., Kuller, L. H., Fried, L. P. and Zandi, P. P. (2008). Knee height and arm span: a reflection of early life environment and risk of dementia. Neurology, 70, 1818-1826.

Prince, M., Acosta, D., Chiu, H., Scazufca, M. and Varghese, M. (2003). Dementia diagnosis in developing countries: a cross-cultural validation study. The Lancet, 361, 909-917.

Prince, M. et al. (in press). Leg length, skull circumference, and the prevalence of dementia in low and middle income countries: a 10/66 population-based cross-sectional survey. International Psychogeriatrics.
A. T. Jotheeswaran, ${ }^{1}$ Joseph D. Williams, ${ }^{1}$ RoBERT STEWART ${ }^{2}$ AND
MARTIN J. PRINCE ${ }^{2}$
${ }^{1}$ Institute of Community Health, Voluntary Health Services, Chennai, India
${ }^{2}$ King's College London, Institute of Psychiatry, Health Service and Population Research Department, London, U.K.
Email: martin.prince@kcl.ac.uk

ure and neurologists perform lumbar puncture rarely.

As anesthetists and scientists involved in researching post-operative cognitive dysfunction (POCD), we have been sampling CSF in patients who receive spinal anesthesia for total hip joint replacement surgery. This can be done simply, quickly and efficiently before the spinal anesthetic is injected. Anesthetists have expertise in lumbar puncture because spinal anesthesia is an integral part of modern anesthetic practice. For example, 